\title{
Uyku bozukluğu farkındalığı, uyku bozukluğu semptomlarının sıklığı ve semptomlar ile ilişkili faktörler: yaşlı popülasyon örneği
}

\author{
Awareness of sleep disorders, frequency of sleep disorders syptoms, the factors \\ associated with syptoms: elderly population sample
}

Zeynep Güneş, Safiye Özvurmaz

Gönderilme tarihi:15.02.2019

Kabul tarihi:02.10.2019

\section{Özet}

Amaç: Bu çalışmanın amaçları; (1) yaşılıarın uyku bozukluğuna ilişkin farkındalık durumlarını, (2) uyku bozukluklarına ilişkin semptom sıklığını, (3) uyku bozukluğu semptomları ile ilişkili faktörleri belirlemektir.

Yöntem: Aile sağıı̆ı merkezine başvuran 353 yaşı ile yapılan kesitsel çalışma uyku bozuklukları, mevcut hastalıkları, kullandıkları ilaçlar ve depresyon durumlarına ilişkin bilgi toplamak için tasarlanmış anket formu kullanılarak yapılmış̧ır. Depresyon kısa form geriatrik depresyon ölçeği-4 ile gündüz uykululuk durumu Epworth uykululuk ölçeği ile değerlendirildi.

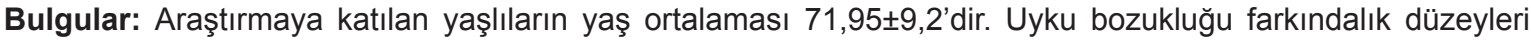
$\% 36,8^{\prime}$ dir. Yaşııların yarıdan fazlası erken uyanmakta ve uykuyu dalmada güçlük yaşamakta ve \%93,8'i uykuyu sürdürememektedir. Yaşlıların yaklaşık 2/3'si tuvalete gitme nedeni ile uykuyu sürdürmede güçlük yaşamaktadıllar. Yaşılırın yaklaşık $1 / 5$ 'inde gündüz uykululuk durumu, korkutucu rüyalar görme, uykuda bağırma, \%42,6'sında horlama gibi uyku bozukluğu semptomları bulunmaktadır. Diyabeti olan, solunum sistemi hastalığı olan, kardiyovasküler hastalığı olanların hastalığı olmayan yaşılıara göre anlamlı olarak uykuya dalmada güçlük yaşamaktadırlar. Depresyonun (uyku bölünmesi hariç) uyku yakınmalarını etkileyen önemli bir faktör olduğu belirlenmiştir.

Sonuç: Yaşılıarın uyku yakınmalarına ilişkin farkındalık düzeyleri düşüktür. Yaşılıarda insomnia semptomları yaygın olarak görülmekte ve depresyon uyku yakınmalarını etkileyen önemli bir faktör olmaktadır.

Anahtar kelimeler: İnsomni, horlama, gündüz aşırı uykululuğu, REM uyku davranış bozukluğu.

Güneş Z, Özvurmaz S. Uyku bozukluğu farkındalığı, uyku bozukluğu semptomlarının sıklığı ve semptomlar ile ilişkili faktörler: yaşı̆ı popülasyon örneği. Pam Tıp Derg 2020;13:41-51.

\begin{abstract}
Purpose: The aims of this study are to determine the awareness of sleep disorders in elderly patients (1), the frequency of the symptoms associated with sleep complaints (2), and to determine the factors related to sleep disorders symptoms (3).

Materials and methods: A cross sectional study of 353 elderly of admitting to family health center was done using designed questionnaire to gather about disorders of sleep, their existing illnesses, medications that they used and their depression status. Depression was assessed by the short form Geriatric Depression Scale-4 and daytime sleepiness was assessed by Epworth Sleepiness Scale.

Results: The mean age of the elderly patients participating in the study is $71.95 \pm 9.2$. Awareness levels of sleep disorder are $36.8 \%$. More than half of the elderly patients wake up early and have difficulties in falling asleep, and $93.8 \%$ cannot maintain sleeping. Approximately $2 / 3$ of the elderly patients have difficulty in maintaining the sleep by reason of going to the toilet. About $1 / 5$ of the elderly patients have daytime sleepiness, nightmares and screaming in the sleep and $42.6 \%$ have symptoms of sleep disorder such as snoring. The elderly patients having diabetes, respiratory system diseases and cardiovascular diseases have difficulties significantly in falling asleep compared to the elderly patients with no diseases. Depression (except sleep disruption) was found to be an important factor affecting sleep complaints.

Conclusion: The level of awareness of sleep disorders among the elderly patients is low. Symptoms of insomnia are common in the elderly patients and depression is an important factor affecting sleep complaints.
\end{abstract}

Key words: Insomnia, snoring, excessive daytime sleepiness, REM sleep behavior disorder.

Güneş Z, Özvurmaz S. Awareness of sleep disorders, frequency of sleep disorders syptoms, the factors associated with syptoms: elderly population sample. Pam Med J 2020;13:41-51.

Zeynep Güneş, Prof. Dr. Aydın Adnan Menderes Üniversitesi Hemşirelik Fakültesi İç Hastalıkları Hemşireliği Anabilim Dalı, AYDIN, e-posta: zgunes@adu.edu.tr (orcid.org/0000-0001-6457-2137) (Sorumlu yazar)

Safiye Özvurmaz, Dr. Öğr. Üye. Aydın Adnan Menderes Üniversitesi Hemşirelik Fakültesi Halk Sağlığı Hemşireliği Anabilim Dalı, AYDIN, e-posta: sozvurmaz@hotmail.com (orcid.org/0000-0002-1842-3058) 


\section{Giriş}

Artan yaşlı nüfusu özelliklerinin, sık karşılaşılan sağlık sorunlarının ve nedenlerinin doğru bir şekilde anlaşılması sorunların önlenmesi ve yönetimini kolaylaştıracaktır. Yaşlılarda uyku bozuklukları sık karşılaşılan bir durumdur [1-4]. Yaşılıarda sık karşılaşılan uyku bozuklukları insomnia, huzursuz bacak sendromu, uykuda periyodik hareket bozukluğu ve obstrüktif uyku apnesi(OSA), hızlı göz hareketleri uykusu davranış bozukluğu olarak sıralanabilir [1, 5-7]. İnsomnia yaşlıların yaklaşık yarısını etkilemektedir $[1,4,8]$. Yaşlılarda OSA görülme sıklığı \%13 ile 32 , huzursuz bacak sendromu görülme sıklığı \%10 ile 35 ve uykuda periyodik hareket bozukluğu görülme sıklığı \%4 ile 11 arasında değişmektedir [911]. Gündüz aşırı uykululuğu (ESS) yaşlılarda sık karşılaşılan uyku problemlerinden biridir, toplumda ve yapılan bir çalışmada yaşılıarın $\% 21$ 'inde ESS belirlenmiştir [12, 13].

Yaşlılarda uyku bozuklukları prevelansı yüksekliğinin nedenleri, yaşlanma ile ilgili sirkadian ritim değişiklikleri, bazı hastalıklar (artrit, diyabet, kardiak ve pulmoner hastalıklar, nörolojik bozukluklar), ağrı, bazı ilaçlar (diüretikler, beta bolokerler, bronkodilatötörler, kortikosteroidler, dekonjestanlar), reçetesiz ilaç kullanımı, depresyon, obesite, emeklilik nedeni ile yaşam tarzı değişikliği, aile üyelerinin kaybı, çevresel faktörler, fiziksel aktivite azığı, kognitif bozulma, uyku hijyenine uymama olarak sıralanmaktadır [5, 12, 13-15].

Tanı konmamış, uygun yönetilmeyen uyku bozuklukları bireylerin fiziksel ve psikolojik sağığını, yaşam kalitesini olumsuz etkilemekte, kaza riskini artırmakta, kişiler arası ilişkilerin bozulmasına neden olmaktadır [16, 17, 19-23].

Uyku bozukluklarının olumsuz sonuçlarını azaltmak için toplum ve sağlık çalışanlarının farkındalığını artırma, uyku bozukluklarının tanılanması ve etkin yönetim için önemlidir [24]. Uyku bozuklukları olan bireyleri belirlerken, uykuyla ilgili bozuklukların 3 ana semptomun veya bunların kombinasyonun sorgulanması gerekir: uykusuzluk veya insomni, gündüz aşırı uykululuk veya hipersomni, gece içinde uyku ya da uyanıklıklar sırasında ortaya çıkan hareket veya davranışlardır $[6,10,12,16,25]$.

Türkiye'de yaşlılarda uyku bozuklukları ile ilişkili semptomları, yaşlılarda uyku bozuklukları ile ilişkili faktörleri araştıran çok fazla çalışma bulunmamaktadır. Bu nedenle bu çalışma yaşıların uyku bozukluğu ile ilgili farkındalık durumlarını, uyku bozukluklarına ilişkin semptomların (uykuya dalmada ve sürdürmede güçlük, erken uyanma, gündüz uykuluğu ve gece uykuda ortaya çıkan hareket ve davranışlar) sıklığını ve yaşlıların tıbbi ve psikolojik durumları ile uyku bozukluklarının semptomları arasındaki ilişkiyi incelemek amacı ile yapıldı.

\section{Gereç ve yöntem}

\section{Evren ve örneklem}

Analitik, kesitsel bir çalışma olan bu araştırmanın evrenini 30/06/2017-30/09/2017 tarihler arasında Aile Sağlığı Merkezi(ASM)'ne herhangi bir sağlık problemi nedeni ile başvuran (2 ve 9 nolu ASM), 65 yaş ve üzeri kadın erkek yaşlılar oluşturdu. Örneklem büyüklüğü ve seçiminde; hedef kitledeki birey sayısının bilinmediği durumlarda kullanılan örneklem hacmi belirleme formülü kullanılarak örneklem hacmi hesaplandı. \%95 güven düzeyinde, 0,05 kabul edilebilir hata ile tahmin edilen uyku bozukluğu görülme oranı ortalama \%32 olarak alındığında örneklem hacmi minimum 334 olarak belirlendi ve toplam 353 yaşı örnekleme alındı [1]. Herhangi bir örneklem seçim yöntemine gidilmemiş olup araştırmanın yapıldığı tarihlerde aile sağlığı merkezine başvuran, araştırmaya katılmayı kabul eden, sağlık durumu stabil olan, demans, alzheimer tanısı olmayan (ASM kayıtlarına göre), iletişimi etkileyen ciddi işitme, görme ve mental problemi olmayan(ASM kayıtlarına göre), terminal dönemde olmayan yaşılır araştırma kapsamına alındı. Araştırmanın verileri, araştırmacı tarafından hazırlanan anket formları ile yüz yüze görüşme tekniği kullanılarak elde edildi.

\section{Veri Toplama Araçları}

Soru formu sosyodemografik özelliklere, uyku bozukluklarına ve bireyin mevcut hastalıkları, kullandıkları ilaçlar, depresyon durumuna ilişkin sorulardan oluştu. Bireyin depresyon durumu kısa form geriatrik depresyon ölçeği (4 maddelik) ile değerlendirildi.

Geriatrik Depresyon Ölçeği-kısa form (GDÖ4): Yaşlı hastalarda depresyon taraması için geliştirilmiştir. Kullanım kolaylığı açısından geliştirilmiş olan 4 soruluk kısa formu kolay ve hızlı uygulanabilmektedir [26, 27]. Shah 
ve arkadaşları [26] tarafından 1996 yılında ölçeğin duyarlılığı \%85 ve özgüllük \%60 olarak belirlenmiştir. Ertan ve arkadaşları 2004 yılında [27] Türk yaşlı popülasyonunda GDÖ-4 için duyarlılığı \%82, özgünlüğü \%86 olarak belirlemişlerdir. GDÖ-4'ün 2-3 kesme puanında en yüksek performansı gösterdiğini belirtmişlerdir.

Yaşlılar REM (rapid eye movement/hızlı göz hareketleri) uykusu davranış bozukluğu, insomnia semptomları (uykuya dalmada ve sürdürmede güçlük, erken uyanma) ve gündüz aşırı uykululuğu açısından sorgulandı. Gündüz aşırı uykuluğun belirlenmesi için Epworth uykululuk skalası kullanıldı.

Epworth uykululuk ölçeği 1991 yılında M.W. Johns tarafından geliştirilmiştir. Bu skala sekiz adet günlük aktivite esnasında uykuya olan yatkınlığı değerlendiren sorulardan oluşmaktadır. Her soru 0-3 puan aralığında puanlanarak, sorulardan elde edilen puanların toplamı değerlendirmeye alınır [28]. Bu skaladan 10'un üzerinde puan alan hastalarda gündüz uykululuk sorunu olduğu kabul edilir [29].

\section{İstatistiksel değerlendirme}

Araştırma verileri Statistical Package for Social Science (SPSS) 18.0 paket programı ile analiz edildi. Verilerin değerlendirilmesinde tanımlayıcı istatistikler, ki kare testi kullanıldı ve grup içi farklılık Mann Whitney $U$ testi ile analiz edildi. Bulgular $p<0,05$ anlamlılık düzey ile yorumlandı.

\section{Bulgular}

Araştırmaya katılan yaşılıarın yaş ortalaması $71,95 \pm 9.2$ olup, $\% 59,8$ 'sini erkekler ve $\% 7,6$ 'sın । üniversite mezunları oluşturmakta olup, $\% 33,7$ 'sinde kardiyo-vasküler hastalık, \%11,3' ünde diyabet ve 1/3'in de depresyon bulunmakta ve $\% 58,1$ 'i ilaç kullanmaktadır (Tablo 1.).

Yaşlıların \%36,8'si kendisinde uyku bozukluğu olduğunu düşünmekte, \%53,5’i erken uyanmakta, \%55' i uykuya dalmada ve büyük bölümü $(\% 93,8)$ uykuyu sürdürmede güçlük yaşamakta, uykuyu sürdürememenin nedenlerini sırası ile tuvalete gitme $(\% 69,1)$, çevresel etmenler $(\% 17,8)$, ruhsal sıkıntı
$(\% 5,1)$, ağrı $(\% 2,3)$ olarak belirtmektedirler. Yaşılıarın \%20'sinde gündüz uykululuk durumu, \%24,7'sinde korkutucu rüyalar görme, \%16,7'sinde uykuda bağırma, \%42,6'sında horlama gibi uyku bozukluğu semptomları bulunmaktadır (Tablo 2).

Uyku bozukluğu olduğunu düşünen yaşlıların uyku bozukluğu olmadığını düşünenlere göre anlamlı düzeyde uykuya dalmada güçlük $(p \leq 001)$, erken uyanma ( $p \leq 001)$, gündüz uykululuk ( $p \leq 005)$ ve uykuda bağırma $(p \leq 001)$ gibi uyku bozukluğu semptomları gösterdiği belirlenmiştir (Tablo 3 ).

Depresyonu olan yaşıların, olmayanlara ve depresyon şüphesi olan yaşlılara göre anlamlı düzeyde uykuya dalmada güçlük, eken uyanma, gündüz uykululuk, korkutucu rüyalar görme, uykuda bağırma gibi uyku bozukluğu semptomları gösterdiği belirlenmiştir $(p \leq 001)$. $\mathrm{Ki}$ kare analiz sonucuna göre depresyon durumu ile uyku bölünmesi arasında anlamlı bir farklılık olduğu, Mann Whitney testi ile farklılığın depresyonu olan yaşlıların depresyonu olmayanlara göre daha fazla uyku bölünmesi yaşamasından kaynaklandığı belirlenmiştir.

Hastalık durumu ile uykuya dalmada güçlük yaşama durumu arasında ki kare analizine göre anlamlı bir ilişki belirlenmiştir. Anlamlılığın kaynağını saptamak için Man Whitney testi yapılmış: Diyabeti olan (Mean Rank:71,75), solunum sistemi hastalığı olan (Mean Rank:67,88), kardiyovasküler hastalığı olanların (Mean Rank:102,57) hastalığı olmayan yaşılara göre anlamlı olarak uykuya dalmada güçlük yaşadığı belirlenmiştir (Tablo 3).

\section{Tartışma}

$\mathrm{Bu}$ çalışmanın amaçları kapsamında; yaşlıların \%36,8'inin uyku bozuklarının farkında olduğu, \%42,6'sının horlama, \%53,5'inin erken uyanma, \%55'inin uykuya dalma ve büyük bölümünün $(\% 93,8)$ uykuyu sürdürme gibi uyku bozukluklarına ilişkin semptom sıklığı deneyimlediği, yaşıların depresyon durumu ile uyku bozukluklarının semptomları arasında anlamlı ilişki olduğu belirlenmiştir. 
Çalışmamıza katılan yaşlıların yaklaşık $1 / 3^{\prime} i$ kendilerinde uyku bozukluğu olduğunun farkındadır. Uyku bozukluklarının farkında olan yaşılarda uyku bozukluklarının farkında olmayanlara göre uykuya dalma, uykuyu sürdürme ve erken uyanma gibi uyku problemleri daha fazladır. Bu bulgu yaşlıların uyku bozukluklarının farkında olduğunu, ancak farkındalığın uyku yakınmalarının sıklığının azaltımasına katkı sağlamadığı şeklinde yorumlanabilir.

Çalışmamıza katılan yaşılarda horlamanın yaygın olarak görüldüğü horlamanın yaşlılarda sık karşılaşıldığını gösteren çalışma bulguları ile sonuçlarımızın benzer olduğu söylenebilir.
Yapılan bir çalışmada 2313 yaşlıdan 1380'i (\%60) habitual horlamasının olmadığını bildirmiştir [2]. Yapılan başka bir çalışmada da yaşlılarda horlama sıklığı \%31,2 olarak bildirilmiştir [30]. Horlama başka bir uyku bozukluğunun (uyku apnesi) belirtisi veya diyabet, artrit gibi hastalıklar ile ilişkili olabilir. Horlama aynı zamanda pozisyon, vücut kitle indeksi ile de ilişkili olabilir [31]. Horlama uykuda solunum bozukluğu ile ilişkili olarak ortaya çıkıyorsa kalp hastalığı ve hipertansiyona neden olarak mortaliteyi artırır, kişinin partnerinde sıkıntı ve rahatsızlık uyandırır, bu nedenle horlayan yaşılıarda horlama nedenlerinin belirlenmesi gerektiği söylenebilir [2, 9, 20, 30].

Tablo 1. Yaşlıların özellikleri $(n=353)$.

\begin{tabular}{|c|c|c|}
\hline \multirow{2}{*}{$\begin{array}{l}\text { Yaş, yıl (mean } \pm S d) \\
\text { Cinsiyet }\end{array}$} & \multicolumn{2}{|c|}{$71,95 \pm 9,2$} \\
\hline & $\mathbf{n}$ & (\%) \\
\hline Kadın & 142 & $(40,2)$ \\
\hline Erkek & 211 & $(59,8)$ \\
\hline \multicolumn{3}{|l|}{ Medeni Durum } \\
\hline Evli & 222 & $(62,9)$ \\
\hline Bekar & 131 & $(37,1)$ \\
\hline \multicolumn{3}{|l|}{ Eğitim Durumu } \\
\hline Okula gitmeyen & 162 & $(45,9)$ \\
\hline İlköğretim & 112 & $(31,7)$ \\
\hline Ortaöğretim & 52 & $(14,7)$ \\
\hline Üniversite & 27 & $(7,6)$ \\
\hline \multicolumn{3}{|l|}{ Çalışma Durumu } \\
\hline Çalışmıyor & 227 & $(64,3)$ \\
\hline Çalışıyor & 126 & $(35,7)$ \\
\hline \multicolumn{3}{|c|}{ Sağlık Durumuna Iliş̧kin Veriler } \\
\hline \multicolumn{3}{|l|}{ Hastalık Durumu } \\
\hline Hastalığı olmayan & 85 & $(24,1)$ \\
\hline Kalp damar hastalı̆ı̆ & 119 & $(33,7)$ \\
\hline Diyabet & 40 & $(11,3)$ \\
\hline Troid hastalığı & 29 & $(8,2)$ \\
\hline Solunum sistemi hastalığı & 28 & $(7,4)$ \\
\hline $\begin{array}{l}\text { Diğer hastalıklar } \\
\text { (fibromiyalji, romatizmal hast ve diğ.) }\end{array}$ & 52 & $(14,7)$ \\
\hline \multicolumn{3}{|l|}{ İlaç kullanma durumu } \\
\hline Kullanmıyor & 148 & $(41,9)$ \\
\hline Kullanıyor & 205 & $(58,1)$ \\
\hline \multicolumn{3}{|l|}{ Depresif semptomlar } \\
\hline Yok & 166 & $(47,0)$ \\
\hline Şüpheli & 70 & $(19,8)$ \\
\hline Var & 117 & $(33,1)$ \\
\hline
\end{tabular}


Tablo 2. Yaşlıların uykuya ait özellikleri.

\begin{tabular}{|c|c|c|}
\hline Yatma zamanı, saat $[$ Mean $\pm S d]$ & \multicolumn{2}{|c|}{$21,24 \pm 5,8$} \\
\hline Sabah uyanma zamanı, saat & \multicolumn{2}{|c|}{$7,54 \pm 3,1$} \\
\hline Uyku bozukluğu farkındalık durumları(n=353) & $\mathrm{n}$ & $\%$ \\
\hline Uyku bozukluğum var & 130 & $(36,8)$ \\
\hline Uyku bozukluğum yok & 223 & $(63,8)$ \\
\hline \multicolumn{3}{|l|}{ Uykuya dalmada güçlük } \\
\hline Var & 194 & $(55)$ \\
\hline Yok & 159 & $(45)$ \\
\hline \multicolumn{3}{|l|}{ Uyku bölünmesi } \\
\hline Var & 331 & $(93,8)$ \\
\hline Yok & 22 & $(6,2)$ \\
\hline \multicolumn{3}{|l|}{ Uyku bölünmesinin nedeni } \\
\hline Tuvalete gitme & 244 & $(69,1)$ \\
\hline Çevresel etmenler & 63 & $(17,8)$ \\
\hline Ruhsal sıkıntı & 18 & $(5,1)$ \\
\hline Ağrı & 8 & $(2,3)$ \\
\hline Neden belirtmeyenler & 20 & $(5,7)$ \\
\hline \multicolumn{3}{|l|}{ Erken Uyanma } \\
\hline Var & 189 & $(53,5)$ \\
\hline Yok & 164 & $(46,5)$ \\
\hline \multicolumn{3}{|l|}{ Gündüz uykululuk } \\
\hline Var & 72 & $(20,4)$ \\
\hline Yok & 281 & $(79,6)$ \\
\hline \multicolumn{3}{|l|}{ Korkutucu rüyalar görme } \\
\hline Evet & 85 & $(24,7)$ \\
\hline Hayır & 256 & $(75,3)$ \\
\hline \multicolumn{3}{|l|}{ Uykuda bağırma } \\
\hline Var & 59 & $(16,7)$ \\
\hline Yok & 294 & $(83,3)$ \\
\hline \multicolumn{3}{|l|}{ Yüksek sesle horlama(n=340) } \\
\hline Var & 145 & $(42,6)$ \\
\hline Yok & 195 & $(57,4)$ \\
\hline
\end{tabular}




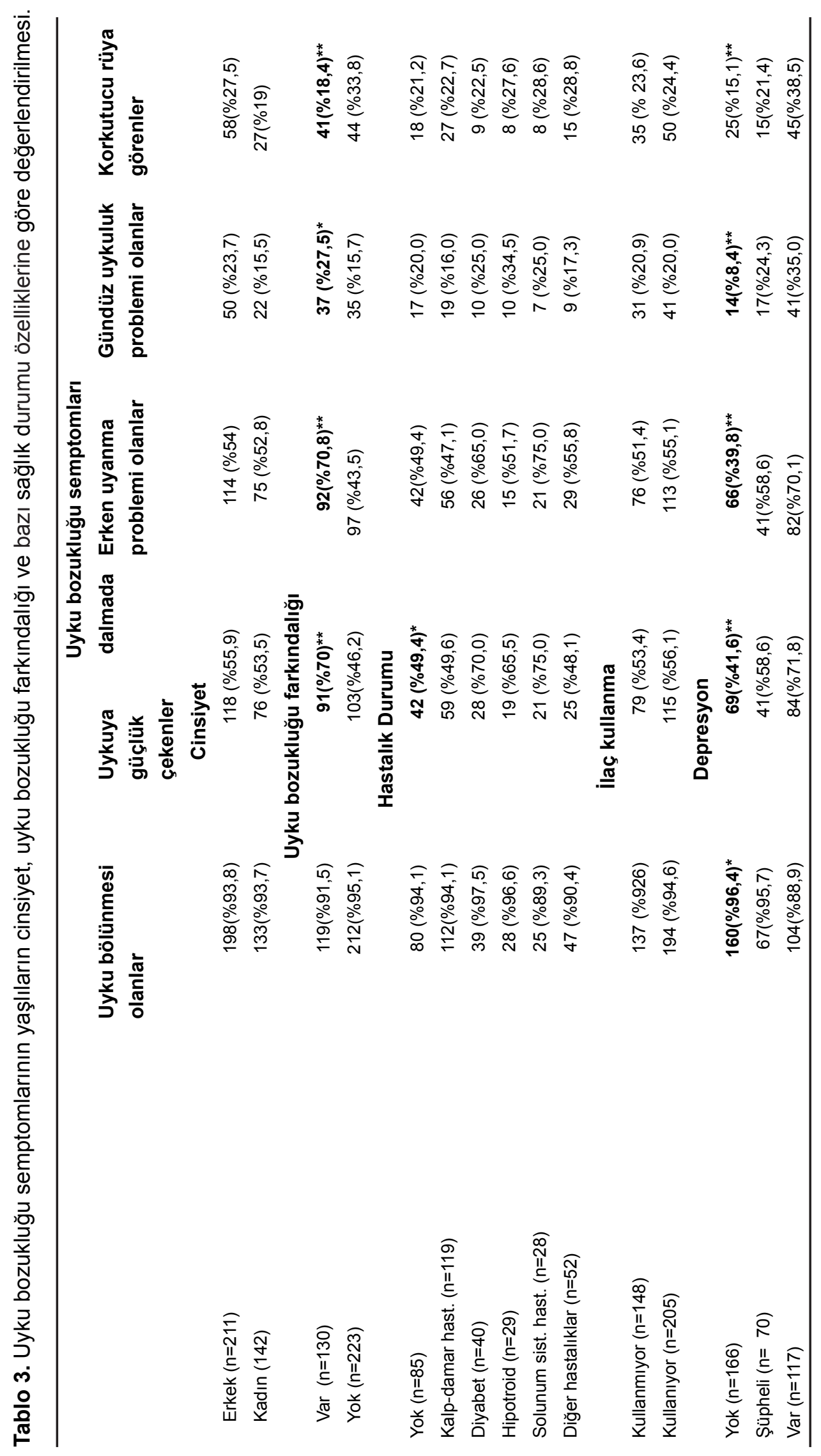




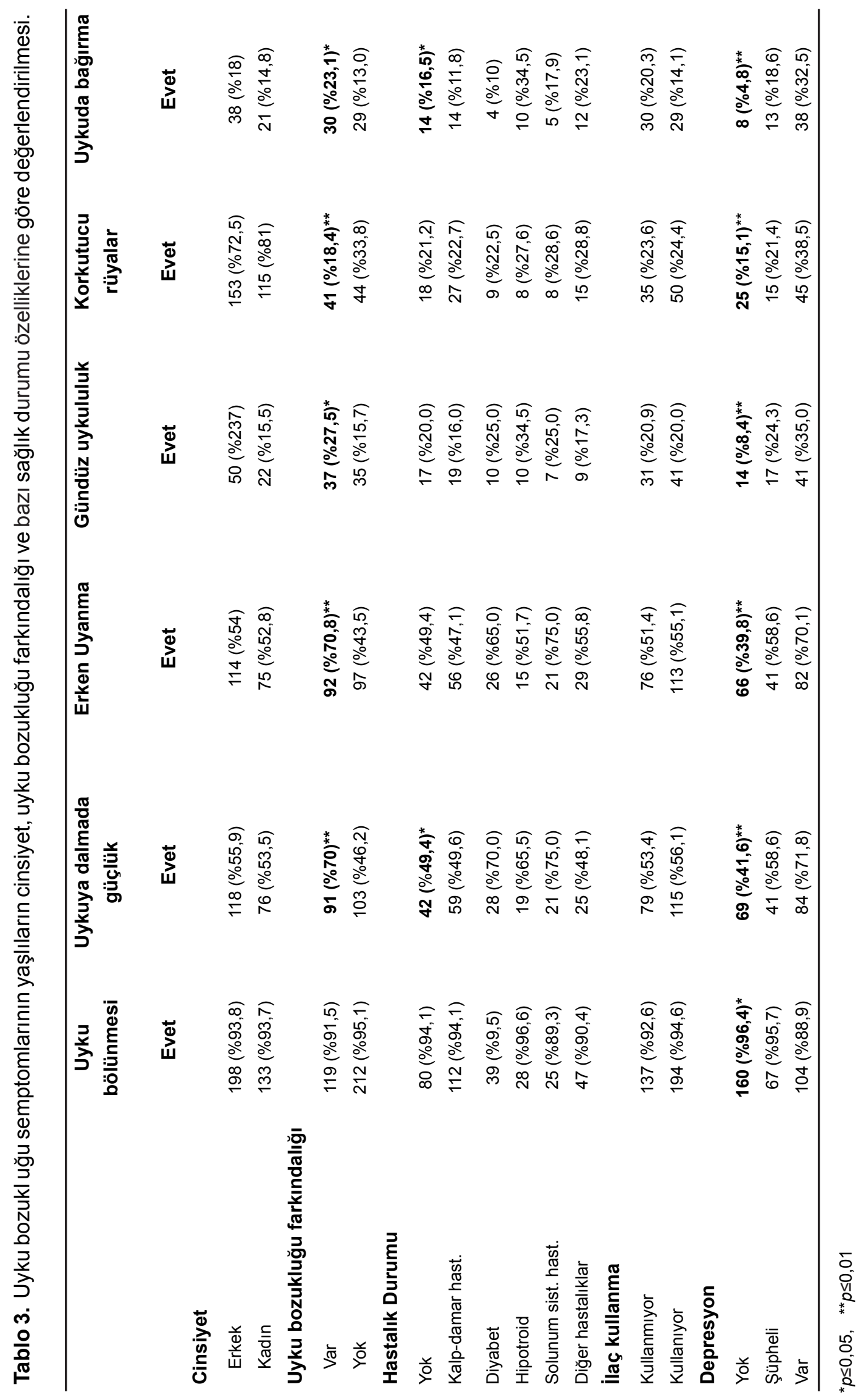


İnsomnia yaşılıarda sık karşılaşılan uyku problemlerinden biridir. Kamel ve Gammack [32] inceleme makalesinde yaşlıların \%50'sinde insomnia görüldüğünü ve çoğunlukla tedavi edilmediğini ve sağlık çalışanlarının nonfarmokolojik yaklaşımları yetersiz kullandığını bildirmektedirler. Crowley [8], Kamel ve Gammack'ın [32] açıklamalarına benzer bir şekilde inceleme makalesinde yaşlıların yaklaşık \%50'sinde insomnia olduğunu bildirmektedir. Farklı ülkelerde yapılan çalışmalar incelendiğinde insonmia, uykuya dalmada güçlük ve uykuyu sürdürmede güçlük yaşama sıklığının \%30 ile \%60 oranında değişim gösterdiği görülmektedir [3, 4, 8, 25, 32, 33]. Gambhir ve arkadaşları [4] Hindistan'da toplum temelli yaptıkları çalışmada yaşlıların \%32'sinde, Tayvan'da yapılan diğer bir çalışmada yaşlıların \%41'inde insomnia olduğu bildirilmiştir [33]. İnsomnia uykuya başlamada, uykuyu sürdürmede güçlük yaşama ve erken uyanma ile karakterizedir [8]. Bizim çalışmamızda yaşlıların \%53,5’i erken uyanmakta, \%55'i uykuyu dalmada ve büyük bölümü $(\% 93,8)$ uykuyu sürdürmede güçlük yaşamaktadır. Çalışma bulgumuz kapsamında yaşlılarda insomnianın başlıca yakınması olan uykuya dalma ve erken uyanma sorununun yaygın olduğunu ve bu konuda yapılan benzer çalışma sonuçlarını desteklediğini söylemek münkündür. Wroble ve arkadaşları [34] primer bakımda yaşılıarın yaklaşık üçte birinin uykuya dalmakta sorun yaşadığını bildirmektedirler. Mısırda yapılan bir çalışmada yaşlılarda insomnia sıklığı $\% 33,6$, uykuya dalma güçlüğü $\% 58,4$, uykuyu sürdürme güçlüğü $\% 53,5$ ve erken uyanma sıklığını \%26 bulunmuştur [35]. Yapılan diğer bir çalışmaya göre yaşlıların \%33,6'sı uykuya dalmada güçlük yaşamaktadır [36]. Subedi [38] yaşlıların \%9,3'ünün uykuya başlamada sorun yaşadığını, \%61,3'ünün uykuyu sürdürmede güçlük yaşadığını bildirmiştir. İnsomnianın nedenleri multifaktöriyeldir, yapılan çalışmalarda solunum sistemi hastalığı olanlarda, kardiak hastalığı olanlarda insomnia görülme sıklığının daha fazla olduğu, aynı zamanda 2001 ile 2010 yıllarını kapsayan kohort çalışmasında insomnianın tip 2 diyabet riskini artırdığı belirtilmiştir [4, 35, 37, 39]. Bizim çalışmamızda da sırası ile diyabet, hipotroidi, kardiovasküler hastalığı olan yaşlıların diğerlerine göre anlamlı şekilde daha fazla uykuya dalmada problem yaşadığı belirlenmiştir.
Bizim çalışmamızda diğer çalışmalara göre dikkat çeken bir bulgu yaşlıların büyük bölümünün uykuyu sürdürmede güçlük yaşadığı ve bunun en önemli nedeninin tuvalete gitme olduğu görülmektedir. Wroble ve arkadaşları [34] yaşlılarda uyku kesintisinin nedenlerinden birinin tuvalete gitme olduğunu belirtmiştir. $\mathrm{Bu}$ bulgu yaşılırın gece sıvı alımı veya sıvı gıdaların kısıtlanmaması gibi uyku hijyen davranışlarının yaşlılarda iyi yönetilmemesi veya bazı hastalıklara, ilaç alımına bağlı ortaya çıkmış olabilir. Çalışmamızda ilaç kullanan yaşlıların \%94,6'sının, ilaç kullanmayanların \%92,6'sının uyku bölünmesi yaşaması bu öngörümüzü desteklediği söylenebilir.

Farklı ülkelerde yapılan çalışmalarda, gündüz uykululuğun yaşlılarda yaygın olarak görüldüğü ve görülme sıklığının $\% 8,9$ ile 32 arasında değiştiği görülmektedir [40, 41-43]. Araştırma bulgumuz kapsamında yaşlılarda gündüz uykululuğun yaygın bir durum olduğunu söylemek mümkündür. Çalışmamızda gündüz uykululuğu görülme sıklığı \%20 olarak bulunmuş olup, diğer ülkelerde yaşlılarda gündüz uykululuk sıklığı ile yapılan bulguları desteklemektedir. Gündüz aşırı uykululuğu görülme sıklığı Lima ve arkadaşlarının [41] Brezilya'da 776 yaşlı ile yaptıkları çalışmada \%21 olarak, Onen ve arkadaşları [42] tarafından Fransa'da yapılan çalışmada epworth uykululuk skalasına göre yaşılırın \%24, Fransa'da 8269 yaşlı ile yapılan çalışmada \%18,7, Amerika'da yapılan bir çalışmada \%22,3 olarak bildirilmiştir [43, 44]. Yapılan bazı çalışmalarda yaşılarda gündüz uykululuk sıklığının çalışma sonucumuzdan daha düşük oranda olduğu görülmektedir. Tardy ve arkadaşları [45] epworth uykululuk skalasına göre yaşılırın \%9,7'sinde, Babar ve arkadaşları [40] \%8,9 gündüz uykululuğu olduğunu belirtmiştir. Çalışma sonucumuz ile Tardy ve arkadaşları [45] ile Babar ve arkadaşlarının [40] çalışma sonucunun farklı olmasının nedeni yaşılırın epworth uykululuk skalasını cevaplamada yaşadıkları güçlük ile açıklanabilir. Onen ve arkadaşları yaptıkları [42] çalışmada tüm katılımcıların gündüz uykululuktan yakınmasına rağmen sadece \%24'ünde gündüz uykululuk olduğunu ve katılımcıların \%60'ının epworth uykululuk skalasında en az bir soruyu yanıtlayamadıklarını bildirmişlerdir.

Uykuda bağırma ve korkutucu rüyalar görme bazen REM uykusu davranış bozukluğunun, 
bazen de nörodejeneratif hastalıkların belirtisi olabileceği gibi yaşlılarda psikolojik sorunlar ile de ilişkili olmaktadır [6, 10, 12, 16, 25, 33]. Anksiyete bozukluğu olan yetişkinler ile yapılan bir çalışmada korkutucu rüyaların anksiyete, depresyon, üzüntü ve kötü yaşam kalitesi ile ilişkili bulunmuştur [46]. Çalışmamızda yaşlıların yaklaşık \%15'i korkutucu rüyalar gördüğünü ve uykuda bağırdığını ifade etmişlerdir. Çalışmamızda depresyonu olan yaşlılarda depresyonu olmayan ve şüpheli depresyonu olanlara göre uykuda korkutucu rüyalar görme ve uykuda bağırma yakınmalarının daha fazla olduğu ve aradaki farkın anlamlı olduğu saptanmıştır. Çalışmamıza katılan yaşlılarda korkutucu rüyalar görme, uykuda bağırmanın bir nedeninin depresyon olduğu söylenebilir. Bulgularımız ve literatür kapsamında korkutucu rüyalar görme ve uykuda bağırma davranışı gösteren yaşııların psikolojik bozukluklar, nörodejeranatif hastalıklar ve REM uyku davranış bozukluğu açısından sorgulanması gerektiği söylenebilir. Hipotrodizm, uyku bozuklukları ve depresyon arasında ilişki olduğu bilinmektedir [1, 5, 6, 8]. Çalışmamızda hipotorid olan hastaların aynı zamanda uykuda bağırma davranışını daha fazla gösterdikleri görülmektedir.

Çalışmamızda depresyonu olan yaşlıların depresyonu olmayan ve şüpheli depresyonu olan yaşılıra göre anlamlı şekilde daha fazla uykuya dalma erken uyanma ve gündüz uykululuk sorunu yaşadıkları belirlenmiştir. Ettensohn ve arkadaşları [47] bazı kişilerde uyku problemleri ve bozukluklarının depresif belirtilerin başlamasından önce başlayabildiğini, diğerlerinde ile depresif belirtilerle birlikte ortaya çıkabildiğini veya depresyon tedavisinden sonra devam edebildiğini belirtmişlerdir. Asltoghiri ve Ghodsi [48] tarafından yapılan çalışmada uyku bozukluklarının depresyon riskini 9 kat artırdığı gösterilmiştir. Luca ve arkadaşları [49] kronik insomnianın etyolojisinde depresyonun rol oynadığını, depresif hastaların \%60-70'inde insomnia bulunduğunu bildirmişlerdir. Gündüz aşırı uykululuğu multifaktöriyeldir. Gündüz aşırı uykululuğu nörolojik, psikolojik, kardiak ve pulmoner hastalıklar ile ilişkili olabileceği gibi obesite, depresyon ileri yaş, yetersiz uyku ile de ilişkilidir [50]. Hayley ve arkadaşlarının [51] 2097 yaş arası 944 kadınla yaptıkları çalışmaya göre depresyon gündüz aşırı uykululuğu ile ilişkilidir. Bulgularımız kapsamında gündüz uykululuk ve depresyon arasındaki ilişki doğrultusunda gündüz uykuluğu olan yaşlılarda depresyon durumunun sorgulanması gerektiğini yada depresyonu olan yaşlılarda gündüz uykululuğunun da sorgulanması gerektiğini söyleyebiliriz.

Sonuç olarak, yaklaşık yaşlıların yası uyku yakınmalarının farkındadır, ancak uyku uyku bozukluğu semptomlarının sıklığı farkındalık düzeylerine göre daha fazladır. Yaşlıların uyku bozukluğunun semptomları ve uyku bozukluklarının sonuçları konusunda bilgilendirilmesinin farkındalıklarını artırmada ve uyku bozukluklarının yönetiminde etkili olacağı düşünülmektedir. Depresyonun uyku yakınmalarını etkileyen bir faktör olduğu dikkate alındığında depresyonu olan yaşlıların uyku bozuklukları açısından sorgulanması yada uyku bozukluğu olan yaşlılarda depresyon durumunun sorgulanması gerektiğini söyleyebiliriz.

$\mathrm{Bu}$ çalışmanın bir takım kısıtlamaları vardır. Verilerin sözel beyana dayalı olarak elde edilmesi; kesitsel tasarım ile yapıldığı için neden- sonuç ilişkisinin kurulmaması; toplum tabanlı olmaması (sadece iki aile sağlığı merkezinde yapılması); ayrıca uyku bozukluğu semptomları ile ilgili cevapların güvenilirliği nedeniyle demans, alzheimer hastalarını da dahil etmedik.

Bulguların genellenebilirliğini arttırmak için, bu çalışma daha büyük örneklem büyüklüğü, geniş çalışma alanı ve objektif veriler ile çoğaltılmalıdır.

Çıkar ilişkisi: Yazarlar çıkar ilişkisi olmadığını beyan eder.

\section{Kaynaklar}

1. Kim WJ, Joo WT, Baek J, et al. Factors associated with insomnia among the elderly in a korean rural community. Psychiatry Investig 2017;14:400-406. https://doi.org/10.4306/pi.2017.14.4.400

2. Endeshaw $Y$, Rice TB, Schwartz AV, et al. Snoring, daytime sleepiness and incident cardiovascular disease in the health, aging, and body composition study. Sleep 2013;36:1737-1745. https://doi.org/10.5665/ sleep. 3140

3. Lindstrom V, Andersson K, Lintrup M, Holst G, Berglund J. Prevalence of sleep problems and pain among the elderly in Sweden. J Nutr Health Aging 2012;16:180183. 
4. Gambhir IS, Chakrabarti SS, Sharma AR, Saran DP. Insomnia in the elderlyd a hospital-based study from North India. JGG 2014;5:117-121. https://doi. org/10.1016/j.jcgg.2014.05.005

5. Cochen V, Arbus C, Soto ME, et al. Sleep disorders and their impacts on healthy, dependent and frail older adults. J Nutr Health Aging 2009;13:322-329.

6. Roepke SK, Ancoli-Israel S. Sleep disorders in the elderly. Indian J Med Res 2010;131:302-310.

7. Bombois S, Derambure P, Pasquier F, Monaca C. Sleep disorders in aging and dementia. J Nutr Health Aging 2010;14:212-217.

8. Crowley K. Sleep and sleep disorders in older adults. Neuropsychol Rev 2011;21:41-45. https://doi. org/10.1007/s11065-010-9154-6

9. Glasser M, Bailey N, McMillan A, Goff E, Morrell MJ. Sleep apnoea in older people. Breathe 2011;7:248256. https://doi.org/10.1183/20734735.021910

10. Dantas FG, Alves Medeiros JL, Soares Farias K, Dantas Ribeiro $\mathrm{Cl}$. Restless legs syndrome in institutionalized elderly. Arq Neuropsiquiatr 2008;66:328-330.

11. Hornyak M, Trenkwalder C. Restless legs syndrome and periodic limb movement disorder in the elderly. J Psychosom Res 2004;56:543-548. https://doi. org/10.1016/S0022-3999(04)00020-0

12. Bittencourt LR, Silva RS, Santos RF, Pires ML, Mello MT. Excessive daytime sleepiness. Braz J Psychiatry 2005;27:16-21. https://doi.org/10/S151644462005000500004

13. Selvi Y, KandeğerA, SayınAA. Gündüz aşırı uykululuğu. Psikiyatride Güncel Yaklaşımlar 2016;8:114-132. https://doi.org/10.18863/pgy.10797

14. Miller CM. Lack of training in sleep and sleep disorders. Am Med Assoc J Ethics 2008;1:560-563. https://doi. org/10.1001/virtualmentor.2008.10.9.medu1-0809

15. Ganga H, Thangaraj Y, Puppala V, Kolla N. Obstructive sleep apnea in the elderly population: atypical presentation and diagnostic challenges. J Intern Med 2009; 8:1-11.

16. Jaiswal SJ, Owens RL, Malhotra A. Raising awareness about sleep disorders. Lung India 2017;34:262-268. https://doi.org/10.4103/0970-2113.205331

17. Jennum P, Santamaria Cano J, Bassetti C, et al. European handbook of neurological management. 2nd Blackwell Publishing Ltd 2011;529-453.

18. Morgenthaler TI, Croft JB, Dort LC, Loeding LD, Mullington JM, Thomas SM. Development of the national healthy sleep awareness project sleep health surveillance ouestions. J Clin Sleep Med 2015;11:10571062. https://doi.org/10.5664/jcsm.5026

19. Sılay $K$, Özkaya $H$, Yalçın $A$, ve ark. Yaşlılarda düşmenin değerlendirilmesi: huzursuz bacak sendromu ile düşme arasında ilişki var mı? Ankara Med J 2016;16:13-19. https://doi.org/10.17098/amj.47556
20. Fava C, Montagnana M, Favaloro EJ, Guidi GC, Lippi G. Obstructive sleep apnea syndrome and cardiovascular diseases. Semin Thromb Hemost 2011;37:280-297. https://doi.org/10.1055/s-0031-1273092

21. Berkeşoğlu Ç. Obstrüktif uyku apne sendromunda gündüz uykululuk ve klinik sonuçlar ile ilişkisi. Türk Uyku Tıbbi Dergisi 2014;3:71-76. https://doi. org/10.4274/jtsm.016

22. Martinez-Garcia MA, Soler Cataluna JJ, Roman Sanchez P, Gonzalez V, Amoros C, Montserrat JM. Obstructive sleep apnea has little impact on quality of life in the elderly. Sleep Med 2009;10:104-111. https:// doi.org/10.1016/j.sleep.2007.11.009

23. Orzeł-Gryglewska J. Consequences of sleep deprivation. Int J Occup Med Environ Health 2010;23:95-114. https://doi.org/10.2478/v10001-010-0004-9

24. Perry GS, Patil SP, Presley-Cantrell LR. Preventing chronic diseases. CDC 2013;10:1-4. https://doi. org/10.5888/pcd10.130081

25. Neikrug AB, Ancoli-Israel S. Sleep disorders in the older Adult - a mini-review. Gerontology 2010;56:181189. https://doi.org/10.1159/000236900

26. Shah A, Phongsathorn V, Bielawska C, Katona C. Screening for depression among geriatric inpatients with short versions of the Geriatric Depression Scale. Int J Geriatr Psychiat 1996;11:915-918. https://doi.org/10.1002/(SICI)10991166(199610)11:10<915::AID-GPS411>3.0.CO;2-H

27. Ertan T, Bugay G, Eker E. Geriatrik depresyon ölçeği kısa formlarının Türk yaşı toplumunda geçerlilik ve güvenilirliği: GDÖ-15, GDÖ-10, GDÖ-4. 5. Poster bildiri: Ulusal Gero-psikiyatri Sempozyumu 10-12 Haziran 2004; İstanbul, Türkiye.

28. Johns MW. A new method for measuring daytime sleepiness: the epworth sleepiness scale. Sleep 1991;14:540-545.

29. İzci B, Ardic S, Firat H, Sahin A, Altinors M, Karacan I. Reliability and validity studies of the Turkish version of the Epworth Sleepiness Scale. Sleep Breath 2008;12:161-168. https://doi.org/10.1007/s11325-0070145-7

30. Adebusoye LA, Ogunbode AM, Olowookere OO. Factors associated with reported snoring among elderly patients attending the geriatric centre in Nigeria. Pan Afr Med J 2014;19:309. https://doi.org/10.11604/ pamj.2014.19.309.5244:

31. Cooke JR, Ancoli-Israel S. Normal and abnormal sleep in the elderly. Handb clin neurol 2011;98:653-665. https://doi.org/10.1016/B978-0-444-52006-7.00041-1.

32. Kamel NS, Gammack JK. Insomnia in the elderly: cause, approach and treatment. Am J Med 2006;119:463-469. https://doi.org/10.1016/j.amjmed.2005.10.051

33. Tsou MT. Prevalence and risk factors for insomnia in community-dwelling elderly in northern Taiwan. JGG 2013:75-79. https://doi.org/10.1016/j.jcgg.2013.02.002 
34. Wroble R, Nagle BA, Cataldi LA. Insomnia in the Elderly: assessment and management in a primary care setting. JCOM 2000;7:50-58.

35. Allah ESA, Abdel-Aziz HR, El-Seoud ARA. Insomnia: prevalence, risk factors, and its effect on quality of life among elderly in Zagazig City, Egypt. J Nurs Educ Pract 2014;4:52-69. https://doi.org/10.5430/jnep. v4n8p52

36. Kitano N, Tsunoda K, Tsuji T, et al. Association between difficulty initiating sleep in older adults and the combination of leisure-time physical activity and consumption of milk and milk products: a crosssectional study. BMC Geriatr 2014;14:118. https://doi. org/10.1186/1471-2318-14-118

37. Anothaisintawee $\mathrm{T}$, Reutrakul $\mathrm{S}$, Van-Cauter $\mathrm{E}$, Thakkinstian A. Sleep disturbances compared to traditional risk factors for diabetes development: systematic review and meta-analysis. Sleep Med Rev 2016;30:11-24. https://doi.org/10.1016/j.smrv. 2015.10.002

38. Subedi RK. Prevalence of insomnia and factors associated with it among the elderly people of sarangdanda VDC in panchthar district. Dhaulagiri Journal of Sociology and Anthropology. 142. https://doi. org/10.3126/dsaj.v4i0.4517

39. Lin CL, Chien C, Chung $\mathrm{CH}$, Wu FL. Risk of type 2 diabetes in patients with insomnia: A populationbased historical cohort study. diabetes Metab Res Rev 2018;34. https://doi.org/10.1002/dmrr.2930

40. Babar S, Enright P, Boyle A, et al. Sleep disturbances and their correlates in elderly Japanese American men residing in Hawai. J Gerontol A Biol Sci Med Sci 2000;55:M406-411.

41. Lima CA, de Souza Soares WJ, Loffredo Bilton T. Corrêa Dias R, Ferrioll E, Rodrigues Perracini M . Correlates of excessive daytime sleepiness in community-dwelling older adults: an exploratory study. Rev Bras Epıdemıol 2015;18:607-617. https://doi.org/10.1590/19805497201500030007

42. Onen F, Moreau T, Gooneratne NS, Petit C, Falissard $\mathrm{B}$, Onen SH. Limits of the epworth sleepiness scale in older adults. Sleep Breath 2013;17:343-350. https:// doi.org/10.1007/s11325-012-0700-8

43. Empana JP, Dauvilliers Y, Dartigues JF, et al. Excessive daytime sleepiness is an independent risk indicator for cardiovascular mortality in community-dwelling elderly: the three city study. Stroke 2009;40:1219-1224. https:// doi.org/10.1161/STROKEAHA.108.530824

44. Carvalho DZ, St Louis EK, Knopman, DS, et al. Association of excessive daytime sleepiness with longitudinal $\beta$-amyloid accumulation in elderly persons without dementia. JAMA Neurol 2018;75:672680. https://doi.org/10.1001/jamaneurol. 2018.0049
45. Tardy M, Gonthier R, Barthelemuy JC, Roche F, Crawford-Achour E. Subjective sleep and cognitive complaints in 65 year old subjects: a significant association. The PROFF cohort. J Nutr Health Aging 2015;19:424-430. https://doi.org/10.1007/s12603014-0547-8

46. Nadorff MR, Porter B, Rhoades HM, Greisinger AJ, Kunik ME, Stanley MA. Bad dream frequency in older adults with generalized anxiety disorder: prevalence, correlates and effect of cognitive behavioral treatment for anxiety. Behav Sleep Med 2014;12:28-40. https:// doi.org/10.1080/15402002.2012.755125:

47. Ettensohn, M, Soto $Y$, Bassi B, Khurshid KA. Sleep problems and disorders in patients with depression. Psychiatric Annals 2016;46:390-395. https://doi. org/10.3928/00485713-20160502-01

48. Asltoghiri M, Ghodsi Z. Study of the relation between sleep disorder and depression at late stage of pregnancy. Procedia-Social and Behavioral Sciences 2011;28:430-434. https://doi.org/10.1016/j. sbspro.2011.11.082

49. Luca A, Luca M, Calandra C. Sleep disorders and depression: brief review of the literature, case report, and nonpharmacologic interventions for depression. Clin Interv Aging 2013;8:1033-1039. https://doi. org/10.2147/CIA.S47230.

50. Slater G, Steier J. Excessive daytime sleepiness in sleep disorders. J Thorac Dis 2012;4:608-616. https:// doi.org/10.3978/j.issn.2072-1439.2012.10.07

51. Hayley AC, Williams LJ, Berk M, Kennedy GA, Jacka FN, Pasco JA. The relationship between excessive daytime sleepiness and depressive and anxiety disorders in women. Aust N Z J Psychiatry 2013;47:772-778. https://doi.org/10.1177/0004867413490036

Teşekkür: Çalışmamıza katılan yaşlılarımıza teşekkür ederiz.

Çalışmamız 4. Uluslararası Multidisipliner Çalışmaları Kongresi'nde sözel bildiri olarak sunulmuştur, 118-19 Ekim 2018, Girne-KKTC.

Araştırmanın yapılabilmesi Adnan Menderes Üniversitesi Tıp Fakültesi Girişimsel Olmayan Klinik Araştırmalar Etik Kurulu'ndan 08.06.2017 tarihinde 26 no'lu karar ile onay alınmıştır. Araştırmanın yürütülmesi için maddi destek ve yardım alınmamıştır. 